\title{
Diversity and Bionomics of Sandflies (Diptera: Psychodidae) of an Endemic Focus of Cutaneous Leishmaniasis in Zagora Province, Southeast of Morocco
}

\author{
Zalalham Al-Koleeby $\left(\mathbb{D},{ }^{1,2}\right.$ Ahmed El Aboudi, ${ }^{2}$ Souhail Aboulfadl $\mathbb{D}^{1},{ }^{1}$ and Chafika Faraj $(\mathbb{D})^{1}$ \\ ${ }^{1}$ Laboratory of Medical Entomology, National Institute of Hygiene, Rabat, Morocco \\ ${ }^{2}$ Plant and Microbial Biotechnology, Biodiversity and the Environment, Faculty of Science, Agdal University, Rabat, Morocco
}

Correspondence should be addressed to Zalalham Al-Koleeby; zalalham2016@gmail.com

Received 30 September 2020; Revised 3 January 2021; Accepted 9 January 2021; Published 23 January 2021

Academic Editor: Bernard Marchand

Copyright ( 2021 Zalalham Al-Koleeby et al. This is an open access article distributed under the Creative Commons Attribution License, which permits unrestricted use, distribution, and reproduction in any medium, provided the original work is properly cited.

\begin{abstract}
The diversity and seasonality for sandflies were studied in 2019 at a focus of zoonotic cutaneous leishmaniasis in Zagora province, southern Morocco. Standardized sampling with CDC light traps was used. A total of 4504 sandflies (4024 Phlebotomus and 480 Sergentomyia) was collected during the study period. Seven species belonging to genus Phlebotomus and six species of genus Sergentomyia were identified. The most abundant species were Ph. papatasi (33.6\%) and Ph. longicuspis (25.7\%), highlighting the risk for local disease transmission foci. The seasonal activity of sandflies extended from April to November, showing two peaks, one in June-July and one, less important, in late-September-October. Abundance was highest during the months May, June, and July and lowest in August, September, and October. Results of this study provide important baseline data for planning control interventions.
\end{abstract}

\section{Introduction}

Leishmaniasis is endemic in Morocco with three distinct parasitic species, Leishmania major, L. tropica, and L. infantum, and 2 disease forms, cutaneous and visceral leishmaniasis. Zoonotic cutaneous leishmaniasis (ZCL) caused by L. major and anthroponotic cutaneous leishmaniasis (ACL) caused by $L$. tropica are the most widespread manifestations of the disease [1]. Major epidemics have occurred recently, according to the National Leishmaniasis Control Program (NLCP); 53193 CL cases were reported between 2008 and 2017 nationwide. ZCL and ACL account, respectively, for 56\% and $44 \%$ of recorded cases. This figure does not reflect the real epidemiological situation since the proportion of the cases detected relative to the estimated cases does not exceed $35 \%$ [2]. In 2018, the NLCP reported, respectively, 8901 and 2909 cases caused by both L. major and L. tropica [1].
Cutaneous leishmaniasis caused by L. major is endemic in the south and the east of the country where Ph. papatasi is the proven vector [3]. The gerbil Meriones shawi is the reservoir host in populated areas [4], but it is suggested that there is a "sylvatic" reservoir system that "feeds" this urban system, with the Psammomys obesus reservoir [5].

More than $80 \%$ of the reported ZCL cases are clustered in the region of Deraa Tafilalt in the southeast of the country made up of five provinces (Errachidia, Tinghir, Midelt, Zagora, and Ouarzazate). Among the 8901 cases identified in 2018,5675 cases $(64 \%)$ were diagnosed in the province of Zagora, located in the south of the region. Most of cases are concentrated in rural areas where public health human resources and infrastructure are limited [6,7]. Surveillance data indicate that the nationwide number of ZCL cases has increased during the last years; such increases can be explained in part by improved diagnosis and case notification 
but are also a result of inadequate approach to disease control. Indeed, the impact of control interventions is very limited in time since efforts and resources are only mobilized in the event of an epidemic situation, which does not assure the sustainability of the actions and results.

Control measures against ZCL in Morocco rely mainly on case management and rodent reservoir control. The standard of care for prevention of disease transmission is environmental management including promotion of improved solid waste disposal practices [8]. Consideration of vector control is important in this case for successful control of leishmaniasis in Morocco. For this reason, knowledge of phlebotomine ecology is necessary. However, data on leishmaniasis vector dynamics in Moroccan ZCL foci are absent, and most research encompasses only the vectors' seasonal abundance in ACL foci [9-17].

The data presented in this paper provide information on the ecology of the most common phlebotomine sand flies in the municipality of Tinzouline, the most important ZCL focus in Zagora province, southeastern Morocco. Results of this study may help to establish effective and appropriate vector control measures by providing information on abundance and seasonal trend of sandfly species in this active focus.

\section{Materials and Methods}

2.1. Study Area. The study was conducted in Tinzouline, a rural municipality in the province of Zagora $\left(30^{\circ} 30^{\prime} 13.8^{\prime \prime} \mathrm{N}\right.$ $\left.6^{\circ} 06^{\prime} 09.4^{\prime \prime} \mathrm{W}\right)$ in southeastern Morocco. Investigations were conducted from April to November 2019, in two villages: Touna Niaaraben situated at an altitude of $910 \mathrm{~m}$ at around $30^{\circ} 37^{\prime} 28.2^{\prime \prime} \mathrm{N} 5^{\circ} 49^{\prime} 56.1^{\prime \prime} \mathrm{W}$ in the northeast and Ksar Mougni situated at an altitude of $775 \mathrm{~m}$ at $30^{\circ} 27^{\prime} 3^{\prime \prime} \mathrm{N}, 5^{\circ} 58^{\prime}$ $26^{\prime \prime} \mathrm{W}$ in the east (Figure 1). Tinzouline climate is typically Saharan, hot in summer with an annual mean maximum temperature of $35^{\circ} \mathrm{C}$ and cold in winter (temperature ranging from $-1^{\circ} \mathrm{C}$ to $-7^{\circ} \mathrm{C}$ ). The rainy season occurs from September to May, with 30-40 rainy days annually and an average annual rainfall of $26 \mathrm{~mm}$ at Touna Niaaraben and $37 \mathrm{~mm}$ at Ksar Mougni.

2.2. Sandfly Collection and Identification. We used CDC light traps to collect sandflies. Two traps were set, in fixed locations, indoor and outdoor in five randomly selected habitations, within the two study villages. Sandflies were collected bimonthly during the sandfly activity season from April to November 2019. During each collection session, trapping was performed over two consecutive nights where traps were operated overnight. The insect catch was checked each morning, and sandflies were sorted and kept in 96\% ethanol. Caught sandflies were counted, sexed, and identified using morphological keys [18] relying on specific morphological features of the pharynx and genitalia (spermathecae in females, external genitalia in males).

2.3. Data Analysis. To characterize the sandfly populations, we calculated four parameters.
(1) The abundance, which is the collected total count of each species

(2) The density, estimated by dividing the total count of sandflies per night by the number of traps set per night

(3) The relative frequency of each species estimated by dividing the collected number of a given species by the total count of all collected species multiplied by 100

(4) The sex ratio, which is the ratio of males to females

The mean number of sandflies captured per trap per night per village was plotted on graphs to track seasonal fluctuations.

\section{Results}

3.1. Diversity and Abundance of Phlebotomine Species. In total, 4504 sandflies (2369 males (52.6\%) and 2135 females $(47.4 \%))$ were collected during the study period from the two localities.

The following 13 species belonging to genera Phlebotomus and Sergentomyia were identified: Phlebotomus (Phlebotomus) papatasi Scopoli; Ph. (Phl.) bergeroti Parrot; Ph. (Par.) alexandri Sinton; Ph. (Par.) sergenti Parrot; P. (Par.) chabaudi Croset, Abonnec et Rioux; Ph. (Par.) kazeruni Theodor and Mesghali; Ph. (Lar.) longicuspis Nitzelescu; Sergentomyia (Sergentomyia) schwetzi Adler; Se. (Ser.) minuta Rodani; Se. (Ser.) fallax Parrot; Se. (par.) africana Newstead; Se. (Gra.) dreyfussi Parrot; and Se. (Sin.) clydei Sinton.

The abundance, the relative frequency, and the sex ratio were calculated for each species, and the results are given in Table 1.

The most abundant species overall in Tinzouline was $\mathrm{Ph}$. papatasi (33.6\%); Ph. longicuspis was the second most abundant species (25.7\%) then Ph. alexandri (25.6\%). These three species account for $84.9 \%$ of all sandflies collected in this survey.

Phlebotomus papatasi was the most abundant species in Mougni locality (44.7\%), while $\mathrm{Ph}$. alexandri was most abundant in Touna locality (41.8\%).

The relative abundance of $\mathrm{Ph}$. longicuspis was (19.8\%) and $(31.7 \%)$, respectively, in Touna and Mougni localities. $P h$. sergenti was detected in the two localities with low relative abundance (less than 3\%).

A total of 480 specimens belonging to Sergentomyia genus was found. Se. fallax was the most abundant Sergentomyia species (with relative abundance $4.6 \%$ among all sandflies).

In Ph. papatasi, Ph. sergenti, Se. fallax, and Se. shwetzi species, males clearly predominated. The ratio of males to females was, respectively, $1: 0.6,1: 0.3,1: 0.5$, and $1: 0.6$. This contrasts with $\mathrm{Ph}$. longicuspis, $\mathrm{Ph}$. alexandri, $\mathrm{Ph}$. bergeroti, and Se. dreyfussi species, where females prevailed with, respectively, $1: 1.2,1: 1.2,1: 6.9$, and $1: 2.9$.

3.2. Sandfly Seasonal Fluctuations. Figures 2 and 3 show the bimonthly capture records for total sandflies as well as for 


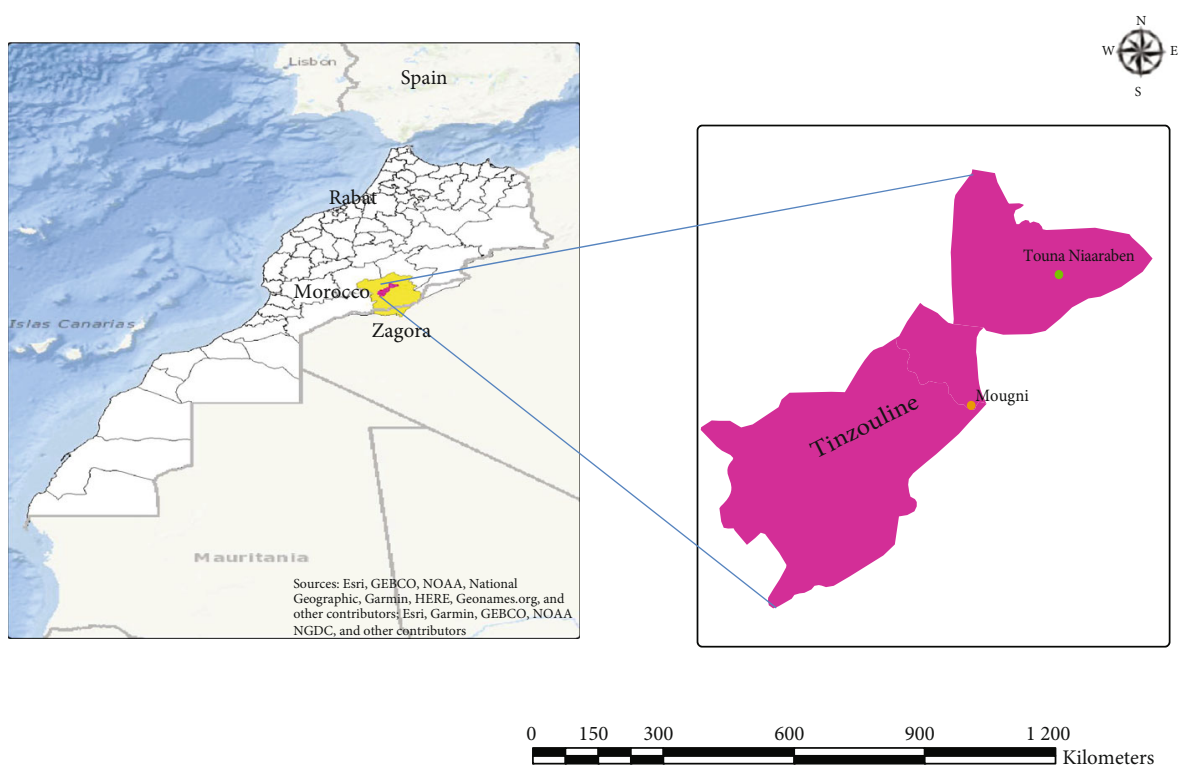

FIgURE 1: Map showing the location of the study sites.

TABle 1: Population, abundance, and sex ratio of sandfly species in the two stations studied.

\begin{tabular}{|c|c|c|c|c|c|c|c|c|c|c|c|c|c|}
\hline & \multicolumn{5}{|c|}{ Touna Niaaraben } & \multicolumn{5}{|c|}{ Ksar Mougni } & \multicolumn{3}{|l|}{ Total } \\
\hline & \multicolumn{3}{|c|}{$\begin{array}{l}\text { No. of collected } \\
\text { sandflies }\end{array}$} & \multirow{2}{*}{$\begin{array}{l}\mathrm{FR} \\
(\%)\end{array}$} & \multirow[t]{2}{*}{ SR } & \multicolumn{3}{|c|}{$\begin{array}{c}\text { No. of collected } \\
\text { sandflies }\end{array}$} & \multirow{2}{*}{$\begin{array}{l}\text { FR } \\
(\%)\end{array}$} & \multirow[t]{2}{*}{ SR } & \multirow{2}{*}{$\begin{array}{l}\text { No. of collected sandflies } \\
\text { (male/female) }\end{array}$} & \multirow{2}{*}{$\begin{array}{l}\text { FR } \\
(\%)\end{array}$} & \multirow[t]{2}{*}{ SR } \\
\hline & Male & Female & Total & & & Male & Female & Total & & & & & \\
\hline Ph. papatasi & 274 & 243 & 517 & 22.7 & $1: 0.9$ & 666 & 331 & 997 & 44.7 & $1: 0.5$ & 1514 & 33.6 & $1: 0.6$ \\
\hline $\begin{array}{l}\text { Ph. } \\
\text { longicuspis }\end{array}$ & 194 & 256 & 450 & 19.8 & $1: 1.3$ & 329 & 378 & 707 & 31.7 & $1: 1.1$ & 1157 & 25.7 & $1: 1.2$ \\
\hline Ph. sergenti & 44 & 15 & 59 & 2.6 & $1: 0.3$ & 49 & 13 & 62 & 2.8 & $1: 0.3$ & 121 & 2.7 & $1: 0.3$ \\
\hline $\begin{array}{l}\text { Ph. } \\
\text { alexandri }\end{array}$ & 458 & 493 & 951 & 41.8 & $1: 1.1$ & 72 & 129 & 201 & 9.0 & $1: 1.8$ & 1152 & 25.6 & $1: 1.2$ \\
\hline $\begin{array}{l}\text { Ph. } \\
\text { chabaudi }\end{array}$ & 0 & 0 & 0 & 0 & 0 & 3 & 2 & 5 & 0.2 & $1: 0.7$ & 5 & 0.1 & $1: 0.7$ \\
\hline Ph. bergeroti & 7 & 38 & 45 & 2.0 & $1: 5.4$ & 2 & 24 & 26 & 1.2 & $1: 12.0$ & 71 & 1.6 & $1: 6.9$ \\
\hline Ph. kazeruni & 0 & 0 & 0 & 0 & 0 & 4 & 0 & 4 & 0.2 & 0 & 4 & 0.1 & 0 \\
\hline Se. shwetzi & 40 & 22 & 62 & 2.7 & $1: 0.6$ & 16 & 9 & 25 & 1.1 & $1: 0.6$ & 87 & 1.9 & $1: 0.6$ \\
\hline Se. minuta & 2 & 9 & 11 & 0.5 & $1: 4.5$ & 19 & 13 & 32 & 1.4 & $1: 0.7$ & 43 & 1.0 & $1: 1.0$ \\
\hline Se. fallax & 84 & 29 & 113 & 5.0 & $1: 0.3$ & 59 & 36 & 95 & 4.3 & $1: 0.6$ & 208 & 4.6 & $1: 0.5$ \\
\hline Se. africana & 2 & 8 & 10 & 0.4 & $1: 4$ & 9 & 7 & 16 & 0.7 & $1: 0.8$ & 26 & 0.6 & $1: 1.4$ \\
\hline Se. dreyfussi & 4 & 19 & 23 & 1.0 & $1: 4.8$ & 10 & 22 & 32 & 1.4 & $1: 2.2$ & 55 & 1.2 & $1: 2.9$ \\
\hline Se. clydei & 3 & 31 & 34 & 1.5 & $1: 10.3$ & 19 & 8 & 27 & 1.2 & $1: 0.4$ & 61 & 1.4 & $1: .1 .8$ \\
\hline Total & 1112 & 1163 & 2275 & 100 & $1: 1.04$ & 1257 & 972 & 2229 & 100 & $1: 0.8$ & 4504 & 100 & $1: 0.9$ \\
\hline
\end{tabular}

FR: relative frequency; SR: sex ratio.

the 3 most abundant species, Ph. papatasi, Ph. longicuspis, and $P h$. alexandri.

In both localities, the seasonal activity of sandflies extended from April to November. Abundance was highest during the months May, June, and July and lowest in August, September, and October. Total sandfly captures over the year showed two peaks, one in June-July and one, less important, in late-September-October. Seasonal abundance of adult $P h$. papatasi in Mougni locality reflected a first peak in June, and then sandfly numbers decreased steadily in JulySeptember as the climate became hotter, then increase slightly to mark a second peak clearly less important than the first in late-September-October. In Touna locality, $\mathrm{Ph}$. papatasi showed a similar trend, but with only one peak in early July.

The bimonthly abundance of Ph. longicuspis and $P h$. alexandri varied greatly between the two localities. Ph. longicuspis showed a bimodal peak pattern in Mougni locality: 


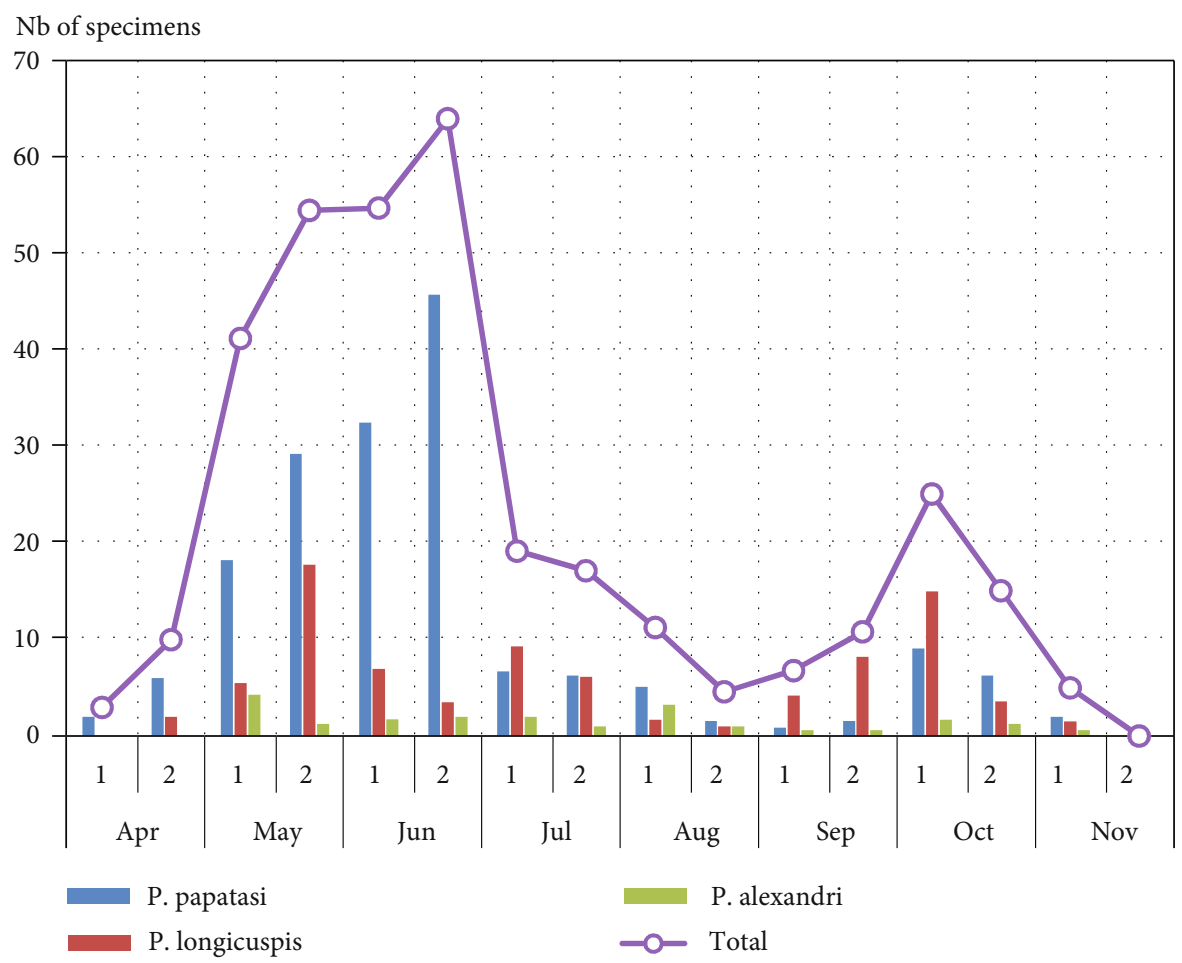

FIGURE 2: Bimonthly capture records for sandflies in Mougni locality.

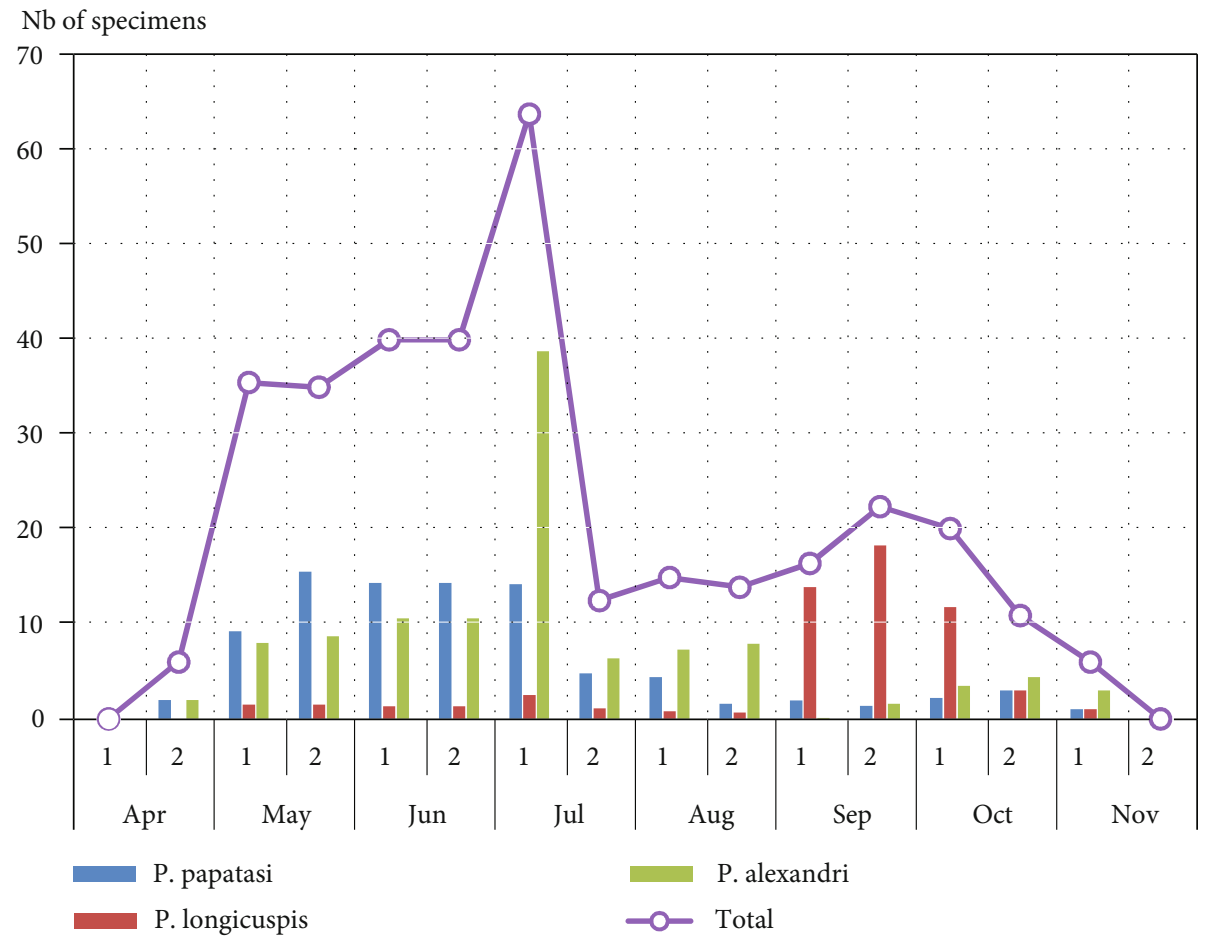

Figure 3: Bimonthly capture records for sandflies in Touna locality.

one in May and one in October, while it showed only one peak in September-October in Touna locality. Ph. alexandri was more abundant in Touna locality, showing one peak towards the beginning of the summer in June-July. In Mougni locality, it has no distinct seasonal pattern, since it was found in low numbers during the entire study period. 


\section{Discussion}

Zagora province has long been known as an endemic CL focus, and the causative agent has been identified as Leishmania major [19]. This paper reports the results of the first entomology-based study conducted in this province in order to provide ecological data regarding the sandfly vector, $P h$. papatasi, and help implement successful control measures.

In this study, thirteen sandfly species were identified from Tinzouline district out of the 24 species previously described in Morocco [20]. The identified species of the genus Phlebotomus belong to the three known subgenus, Phlebotomus (Ph. papatasi and Ph. bergeroti), Paraphlebotomus (Ph. sergenti, Ph. alexandri, Ph. chabaudi, and Ph. kazeruni) and Larroussius (Ph. longicuspis). All of them have been already observed in previous studies in southern Morocco $[13,21-23]$.

The six species belonging to Sergentomyia genus (Se. shwetzi, Se. minuta, Se. fallax, Se. africana, Se. dreifussi, and Se. clydei) were weakly represented in sandfly fauna caught in this area. This finding is in line with observations made in other Moroccan CL endemic areas. These species are known to be less abundant in anthropic environments mainly inside and in the vicinity of human dwellings [13-17].

Except for Ph. chabaudi and Ph. kazeruni that were observed in Touna and not in Mougni, there was no difference in sandfly species diversity between the two villages. Three species encountered in the Tinzouline focus are involved in the transmission of the different Leishmania parasites. Ph. papatasi is considered the main vector of $L$. major in the south and southeast of the country, Ph. longicuspis is a known vector of $L$. infantum spread mainly in northern regions, and Ph. sergenti, the vector of CL caused by $L$. tropica, is reported mainly in the center of the country [5]. Two of these three species (Ph. papatasi and Ph. longicuspis) represented more than $59 \%$ of all collected sandflies, highlighting the risk for local disease transmission foci. Phlebotomus sergenti was scarce (2.7\%). In a similar study conducted in a $L$. tropica focus in Tinghir province, bordering Zagora province, Faraj et al. [13] found that Ph. papatasi was the most abundant sandfly (45.7\%), followed by Ph. sergenti (27.8\%) then Ph. longicuspis (13.5\%), while Ph. alexandri was the least-collected Phlebotomus species (1.1\%).

Phlebotomus papatasi was found to be more abundant in the Mougni locality with $45 \%$ of the catch. It was less abundant in Touna (23\%). This can be explained by the difference in altitude between the two localities; in fact, this species prefers to live in plain areas rather than in mountains [24]. In a study conducted in southwestern Morocco [25], authors reported negative association between altitude and abundance of Ph. papatasi. They indicated that this fly was predominant in plains (400-599 m), rare at the other altitudes, and absent from $1200 \mathrm{~m}$ a.s.l.

The adults of $P h$. papatasi were active for eight months (April-November) with a bimodal evolution in Mougni and only one peak in Touna. Few studies have been done on the population dynamic of this species. The period of its activity was determined in Marrakech in the southwest where it was active throughout the year showing two peaks of density, the first in June and the second in November [11]. The same period of activity was postponed in Tinghir adjacent to Zagora, with two peaks in both June and August-September [13].

Phlebotomus alexandri was the most abundant species in Touna (42\%). It was observed from April to November with one peak towards the beginning of the summer in July. This species prefers regions with a high percentage of relative humidity and warmer niches [26]. It is generally distributed in mountainous regions and sylvatic biotope [22].

Phlebotomus longicuspis flies were collected from April to November in the two localities showing a bimodal peak pattern in Mougni locality, one in May and one in October, and only one peak in September-October in Touna locality. The occurrence with considerable density and long activity period of this confirmed VL vector is a cause for concern and indicates the high potential risk of L. infantum transmission in the studied areas. In Tinghir province, this species showed only one peak in August [13], the same in Chichaoua province, southwest of Morocco; the density peak was in August-September [10]. According to Guernaoui et al. [25], Ph. longicuspis is more abundant between 600 and $799 \mathrm{~m}$ altitude while its density became much lower outside this range. These results are consistent with ours since this species was more abundant in the Mougni locality at an altitude of 775 meters.

\section{Conclusion}

This detailed study on the abundance and seasonal trends of $P h$. papatasi, the vector of cutaneous leishmaniasis caused by L. major in Morocco, provides important baseline data for planning control interventions. According to the results of this study, control actions programmed twice a year at the time of density peaks would make it possible to control the transmission of the disease if these are correctly coordinated with case treatment and application of appropriate reservoir control. Raising public awareness of disease prevention measures is also important for the success of an epidemic control program. Entomological studies on the distribution and dynamics of vectors are important. They must be carried out regularly in different regions in order to provide decision-makers with up-to-date data.

\section{Data Availability}

The data used in this study are included within the article.

\section{Conflicts of Interest}

The authors declare that they have no competing interests.

\section{Acknowledgments}

The authors warmly thank the staff of medical delegations of Zagora for their kind assistance in the fieldwork. In addition, they send big thanks to Lakraa El Housseine, Elkohli Mohammed, Othmane Trimasse, and Karima El Mouhdy for their helpful contribution in sandfly identification. 


\section{References}

[1] Moroccan Ministry of Public Health, Rapport annuel d'activités, Direction de l'épidémiologie et de lutte contre les maladies, Rabat, Morocco, 2019.

[2] S. Bouhout, B. Bardri, M. Abandouni, I. Chelloufi, M. Youbi, and A. Maaroufi, "Programme national de lutte contre les leishmanioses," Bulletin d'épidémiologie et de santé publique, vol. 56, no. 76, pp. 17-18, 2018.

[3] J. A. Rioux, E. Guilvard, J. Dereure et al., "Infestation naturelle de Phlebotomus papatasi (Scopoli, 1786) par Leishmania major MON-25. A propos de 28 souches isolées dans un foyer du Sud Marocain," in Leishmania. Taxinomie Phylogenèse. Applications éco épidémiologiques. (Coll. Int. CNRS/INSERM, 1984), pp. 471-480, IMEEE, Montpellier, France, 1986.

[4] J. A. Rioux, F. Petter, O. Akalay et al., "Meriones shawi (Duvernoy, 1842) (Rodentia, Gerbillidae), réservoir de Leishmania major Yakimoff et Shokhor, 1914 dans le Sud Marocain," Comptes Rendus des Séances de l'Académie des sciences. Série III, vol. 294, no. 11, pp. 515-517, 1982.

[5] D. Chaara, N. Haouas, J. P. Dedet, H. Babba, and F. Pratlong, "Leishmaniases in Maghreb: an endemic neglected disease," Acta Tropica, vol. 132, no. 1, pp. 80-93, 2014.

[6] J. Alvar, S. Yactayo, and C. Bern, "Leishmaniasis and poverty," Trends in Parasitology, vol. 22, pp. 552-557, 2006.

[7] M. M. M. El Alem, M. Hakkour, A. Hmamouch et al., "Risk factors and prediction analysis of cutaneous leishmaniasis due to Leishmania tropica in southwestern Morocco," Infection, Genetics and Evolution, vol. 61, pp. 84-91, 2018.

[8] C. Faraj, J. Yukich, E. B. Adlaoui et al., "Effectiveness and cost of insecticide treated bed nets and indoor residual spraying for the control of cutaneous leishmaniasis: a cluster randomized control trial in Morocco," American Journal of Tropical Medicine \& Hygiene, vol. 94, no. 3, pp. 679-685, 2016.

[9] N. Guessous-Idrissi, S. Chiheb, A. Hamdani et al., "Cutaneous leishmaniasis: an emerging epidemic focus of Leishmania tropica in north Morocco," Transactions of the Royal Society of Tropical Medicine \& Hygiene, vol. 91, no. 6, pp. 660-663, 1997.

[10] S. Guernaoui, A. Boumezzough, B. Pesson, and G. Pichon, "Entomological investigations in Chichaoua: an emerging epidemic focus of cutaneous leishmaniasis in Morocco," Journal of Medical Entomology, vol. 42, no. 4, pp. 697-701, 2005.

[11] S. Boussaa, S. Guernaoui, B. Pesson, and A. Boumezzough, "Seasonal fluctuations of phlebotomine sand fly populations (Diptera: Psychodidae) in the urban area of Marrakech, Morocco," Acta Tropica, vol. 95, no. 2, pp. 86-91, 2005.

[12] K. Ramaoui, S. Guernaoui, and A. Boumezzough, "Entomological and epidemiological study of a new focus of cutaneous leishmaniasis in Morocco," Parasitology Research, vol. 103, no. 4, pp. 859-863, 2008.

[13] C. Faraj, E. B. Adlaoui, S. Ouahabi et al., "Distribution and bionomic of sand flies in five ecologically different cutaneous leishmaniasis foci in Morocco," ISRN Epidemiology, vol. 2013, Article ID 145031, 8 pages, 2013.

[14] H. el Miri, M. Rhajaoui, O. Himmi, S. Ouahabi, A. Benhoussa, and C. Faraj, "Etude entomologique de cinq foyers de leishmaniose cutanée dans la province de Sidi Kacem au nord du Maroc," Annales de la Société entomologique de France (N.S.), vol. 49, no. 2, pp. 154-159, 2013.

[15] K. Lahouiti, A. El OualiLalami, S. Maniar, and K. Bekhti, "Seasonal fluctuations of phlebotomines sand fly populations (Diptera: Psychodidae) in the Moulay Yacoub province, centre
Morocco: effect of ecological factors," African Journal of Environmental Science and Technology, vol. 7, no. 11, pp. 10281036, 2013.

[16] F. Z. Talbi, A. el Ouali Lalami, A. Janati Idrissi, F. Sebti, and C. Faraj, "Leishmaniasis in central Morocco: seasonal fluctuations of phlebotomine sand fly in Aichoun locality, from Sefrou province," Pathology Research International, vol. 2015, Article ID 438749, 4 pages, 2015.

[17] M. Zouirech, C. Faraj, and D. Belghyti, "Entomological and epidemiological investigations of an emerging focus of cutaneous leishmaniasis in Bzou, Morocco," Entomologie Faunistique, vol. 68, pp. 201-211, 2015.

[18] C. Faraj and O. Himmi, "Clés morphologiques pour l'identification des phlébotomes du Maroc (Diptera: Psychodidae: Phlebotominae)," Bulletin de la Société de Pathologie Exotique, 2020.

[19] A. el Hamouchi, O. Daoui, M. Ait Kbaich et al., "Epidemiological features of a recent zoonotic cutaneous leishmaniasis outbreak in Zagora province, southern Morocco," PLoS Neglected Tropical Diseases, vol. 13, no. 4, article e0007321, 2019.

[20] C. Faraj and O. Himmi, "Updated list of Phlebotominae (Diptera: Psychodidae) from Morocco," Bulletin de la société de pathologie exotique, vol. 112, pp. 296-301, 2019.

[21] J. A. Rioux, O. Akalay, J. Perrieres et al., "L'évaluation écoépidémiologique du «risque leishmanien» au Sahara atlantique marocain. Intérêt heuristique de la relation «Phlébotomes-bioclimats»," Ecologia Mediterranea, vol. 23, no. 3, pp. 73-92, 1997.

[22] J. A. Rioux, P. Rispail, G. Lanotte, and J. Lepart, "Relations phlébotomes-bioclimats en écologie des leishmanioses Corollaires épidémiologiques. L'exemple du Maroc," Bulletin de laSociété Botanique de France, vol. 131, no. 2-4, pp. 549-557, 2014.

[23] S. Boussaa, M. Neffa, B. Pesson, and A. Boumezzough, "Phlebotomine sand flies (Diptera: Psychodidae) of southern Morocco: results of entomological surveys along the Marrakech-Ouarzazat and Marrakech-Azilal roads," Annals of Tropical Medicine and Parasitology, vol. 104, no. 2, pp. 163170, 2010.

[24] G. C. Muller, V. D. Kravchenko, L. Rybalov, J. C. Beier, and Y. Schlein, "Characteristics of resting habitats of adult Phlebotomus papatasi in Neot Hakikar, an oasis south of the Dead Sea," Journal of Vector Ecology, vol. 36, Suppl 1, pp. S179S186, 2011.

[25] S. Guernaoui, A. Boumezzough, and A. Laamrani, "Altitudinal structuring of sand flies (Diptera: Psychodidae) in the HighAtlas mountains (Morocco) and its relation to the risk of leishmaniasis transmission," Acta Tropica, vol. 97, no. 3, pp. 346351, 2006.

[26] A. R. Zahraei-Ramazani, S. Yousefi, Y. Rassi et al., "Diversity of Phlebotomine sand flies (Diptera: Psychodidae) in mountainous and plain areas of an endemic focus of anthroponotic cutaneous leishmaniasis in Iran," Asian Pacific Journal of Tropical Biomedicine, vol. 10, pp. 201-207, 2020. 